\title{
New Attenuation Relationship for Peak Ground and Pseudo-Spectral Acceleration of Normal-Faulting Earthquakes in Offshore Northeast Taiwan
}

\author{
Yu-Ju Wang ${ }^{1,2, *}$, Ya-Ting Lee ${ }^{2}$, Kuo-Fong $\mathrm{Ma}^{2}$, and Yuan-Chieh $\mathrm{Wu}^{3}$ \\ ${ }^{1}$ Institute of Earth Sciences, Academia Sinica, Taipei, Taiwan, R.O.C. \\ ${ }^{2}$ Department of Earth Sciences, National Central University, Taoyuan, Taiwan, R.O.C. \\ ${ }^{3}$ Institute of Nuclear Energy Research, Atomic Energy Council, Executive Yuan, Taoyuan, Taiwan, R.O.C.
}

Received 8 April 2015, revised 13 August 2015, accepted 17 August 2015

\begin{abstract}
Ground motions from normal-faulting earthquakes are generally considered to be smaller than those of strike-slip and thrust events. On 11 April 2011 a crustal normal-faulting earthquake [the Fukushima earthquake $\left(\mathrm{M}_{\mathrm{w}} 6.6\right)$ ] occurred in Eastern Japan. The peak ground acceleration (PGA) observed was considerably higher than the predictions of several ground-motion prediction equations (GMPEs), which were derived mainly from thrust or strike-slip earthquakes. In northeast Taiwan, the tectonic structure of the Ryukyu Arc and the Okinawa Trough typically entail normal-faulting earthquakes. Because of the normal-faulting earthquakes relevance to ground motions and nuclear power plant sites in northeast Taiwan, we evaluated the impact of the ground motion of normal-faulting earthquakes in offshore northeast Taiwan using a newly constructed attenuation relationship for PGA and pseudo-spectral acceleration (Sa). We collected 832 records from 13 normal-faulting earthquakes with focal depths of less than $50 \mathrm{~km}$. The moment magnitude $\left(\mathrm{M}_{\mathrm{w}}\right)$ of the 13 events was between $4-6$. The $\mathrm{Sa}$ and PGA of normal-faulting earthquakes offshore northeast Taiwan determined with the newly constructed attenuation relationship were higher and lower, respectively, than those obtained using attenuation equations commonly used in the Taiwan subduction zone.
\end{abstract}

Key words: GMPE, Normal-faulting, Attenuation, PGA, Sa, Taiwan

Citation: Wang, Y. J., Y. T. Lee, K. F. Ma, and Y. C. Wu, 2016: New attenuation relationship for peak ground and pseudo-spectral acceleration of normal-faulting earthquakes in offshore northeast Taiwan. Terr. Atmos. Ocean. Sci., 27, 43-58, doi: 10.3319/TAO.2015.08.17.01(T)

\section{INTRODUCTION}

Earthquakes are disasters that can cause severe damage and destruction. To mitigate the seismic hazard from moderate to large earthquakes, assessing the degree of ground shaking and designing earthquake-resistant buildings is critical. A robust and reliable model is essential to estimate ground motion and data for the attenuation model must be carefully processed. To develop a set of comprehensive and broadly accepted ground-motion prediction equations (GMPEs) for the United States, the Next Generation Attenuation (NGA) program coordinated by the Pacific Earthquake Engineering Research Center (PEER) established a strong motion database including most moderate to large crustal earthquakes in worldwide active tectonic regions. 3551 records were

\footnotetext{
* Corresponding author

E-mail:wangzu885@gmail.com
}

contained in the NGA database in 2006 (Chiou and Youngs 2008). The data includes approximately $28 \%$ strike-slip event records, $65 \%$ reverse-faulting event records, and $5 \%$ normal-faulting event records. By 2014 (NGA-West 2 project) the database contained 21336 records (Ancheta et al. 2014). The database enabled researchers to develop numerous GMPEs to evaluate for specific faulting types by controlling for the dummy variables in the equations (Abrahamson and Silva 2008; Boore and Atkinson 2008; Chiou and Youngs 2008; Abrahamson et al. 2013). Thrusting interplate earthquakes were the majority of shallow earthquake sources used in subduction zones to develop attenuation models for peak ground acceleration (PGA) and pseudo-spectral acceleration (Sa) (Atkinson and Boore 2003; Kanno et al. 2006; Abrahamson et al. 2015). The Taiwan NGA (TNGA) Project (Lee et al. 2009) assembled the Taiwan Strong Ground 
Motion records between 1992 - 2008 provided by the Taiwan Central Weather Bureau (CWB). The well-processed 13433 records comprise $61 \%$ thrust faulting event records, $32 \%$ strike-slip event records, and 7\% normal-faulting event records for crustal earthquakes. A total of 9211 earthquake records involve subduction zones; $65 \%$ involve thrust faulting, 22\% involve strike-slip, and $13 \%$ involve normal faulting. In previous studies on Taiwan GMPEs, most equations did not specifically consider the earthquake source faulting types (such as Chang et al. 2001; Wu et al. 2001; Liu and Tsai 2005). Lin et al. (2012) adopted the NGA method using dummy variables to denote the crustal earthquake faulting type in the equations. The GMPEs for shallow subduction zone earthquakes ( $<50-\mathrm{km}$ depth) only considered thrusting interplate earthquakes. This suggests that most GMPEs that quantify the ground shaking intensity using shallow seismic sources were determined using thrust-faulting and strikeslip earthquakes.

According to previous studies (McGarr 1984; Campbell 1997; Brune and Anooshehpoor 1999; Brune 2000; Shi et al. 2003), normal-faulting earthquakes are generally assumed to exhibit lower PGA than thrust or strike-slip events. The assumed weaker ground shaking and limited number of records for normal-faulting earthquakes has resulted in less effort invested in characterizing the ground-motion of normal-faulting earthquakes.

On 11 April 2011 the Fukushima-ken-hamadori-no earthquake (Fukushima earthquake; $\mathrm{M}_{\mathrm{JMA}}: 7.0 ; \mathrm{M}_{\mathrm{w}}: 6.6$ ) occurred in Iwaki City, Japan, which is situated approximately $250 \mathrm{~km}$ southwest of the $2011 \mathrm{M}_{\mathrm{w}} 9.0$ Tohoku earthquake epicentre. The focal depth was $6 \mathrm{~km}$ according to the K-net and KiK-net catalogues. The earthquake ruptured two subparallel faults, the northwest-trending Yunodake fault and the north-northwest-trending Itozawa fault. Two clear surface ruptures appeared along the two faults, 15 and $14 \mathrm{~km}$ long, respectively, exhibiting a predominantly normal slip sense, down to the west. The maximal vertical offset on the Yunodake fault measured approximately $0.8 \mathrm{~m}$, whereas that on the Itozawa fault measured approximately $2.1 \mathrm{~m}$. The rupture triggered numerous rock falls and landslides, causing structural damage and resulting in four human casualties (Toda and Tsutsumi 2013).

Si et al. (2012) and Anderson et al. (2013) analyzed the horizontal PGA and peak ground velocity (PGV) of the Fukushima earthquake and its associated normal-faulting fore- and aftershocks. A higher ground motion compared with the prediction of several GMPEs (Si and Midorikawa 2000; Abrahamson and Silva 2008; Boore and Atkinson 2008; Campbell and Bozorgnia 2008; Chiou and Youngs 2008) was observed with a factor of 2.3 - 3.7 in acceleration and $1.4-1.8$ in velocity. The stress drop of the Fukushima earthquake was considered typical of crustal events for normal-faulting earthquakes in Japan and worldwide (Anderson et al. 2013). The small simultaneous contributions from the sequential ruptures of two subparallel faults, which were evidenced by source inversion, did not constitute a viable explanation for the high ground motion. Regarding adjusting the PGA and PGV with customized site terms, the residuals were greatly reduced, but positive deviation remained.

The Fukushima earthquake has drawn attention to the anomalously high PGA and PGV of normal-faulting earthquakes. Taiwan is located at the collision boundary between the Philippine Sea Plate (PSP) and the Eurasian Plate (EUP). Two converging systems, the Ryukyu subduction zone resulting from the subduction of the PSP to the EUP, and the Manila subduction zone resulting from the subduction of the EUP to the PSP, are offshore northeast and southwest Taiwan, respectively. The Ryukyu arc-trench system comprises the Ryukyu Arc, a row of islands and an active volcanic belt. The Okinawa Trough lies along the Ryukyu arc-trench system (Fig. 1), which is formed by the extension of the Eurasian continental lithosphere and constitutes a young backarc basin. Several en-echelon extensional grabens with active faults have been identified in this region, suggesting that the Okinawa Trough is still in the rifting stage prior to spreading (Shinjo 1999). Sibuet et al. (1998) mapped numerous normal faults based on the swath-bathymetric and seismic data. The $\mathrm{M}_{\mathrm{w}}$ of normal-faulting earthquakes observed in this area in previous decades were mainly between $4-5$, which was considered only a minor earthquake hazard. However, normal-faulting earthquakes exhibiting moderate intensities may cause substantial damage; for instance, the event of $1976\left(\mathrm{M}_{\mathrm{w}}\right.$ 4.7) in Denizli, Turkey (Ates 1985) and the events (swarm) of $1972\left(\mathrm{M}_{\mathrm{w}} 4.4\right.$ - 4.9) in Ancona, Itlay (Lander 1973). The Sanchiao Fault, which was announced by the Taiwan Central Geologic Survey (CGS) in 2010, is the longest normal fault, extending from the Taipei Basin to the East China Sea. The fault length of the Sanchiao Fault determined by the CGS implies the possibility of an intense normal-faulting earthquake. Therefore, the threat of normal-faulting earthquakes to highly populated Northern Taiwan should be considered.

To examine the effect of strong ground motion, specifically from normal-faulting earthquakes, we investigated the horizontal PGA and Sa of the normal-faulting events offshore northeast Taiwan. A new normal-faulting earthquake attenuation relationship for PGA and Sa with 105 periods was developed. Our findings provide crucial insights regarding the safety of nuclear power plants (NPPs) and infrastructure in Northern Taiwan.

\section{DATA}

The Taiwan Strong Motion Instrumentation Program (TSMIP) was initiated in 1991 by the CWB. The TSMIP network is designed to monitor the ground shaking of strong earthquakes and collect high-quality data for use in engineering and seismology. Except in mountainous areas, the monitoring stations are densely spaced approximately $5 \mathrm{~km}$ 
apart on average and only $3 \mathrm{~km}$ apart in urban areas. Since 1993 the TSMIP has been operating the strong-motion network using over 700 stations, which have recorded thousands of earthquakes with $\mathrm{M}_{\mathrm{L}}>4$ in and around Taiwan. The instruments have dynamic ranges from 12, 16, and 24-bit force-balance accelerometer (FBA) sensors with sampling rates of 200 - 250 points per second.

In contrast to the TSMIP, the Broadband Array in Taiwan for Seismology (BATS) was established by the Institute of Earth Sciences (IES), Academia Sinica in 1992 to routinely estimate the source parameters of earthquakes occurring in the region. The Centroid-Moment-Tensor solution of earthquakes with magnitudes higher than 4 after 1995 is catalogued online. After the 1999 Chi-Chi earthquake in Taiwan the BATS incorporated additional stations deployed by the CWB, increasing the total number of BATS stations to 64 and covering both mountainous areas and islands. The additional stations enhance the event focal mechanism

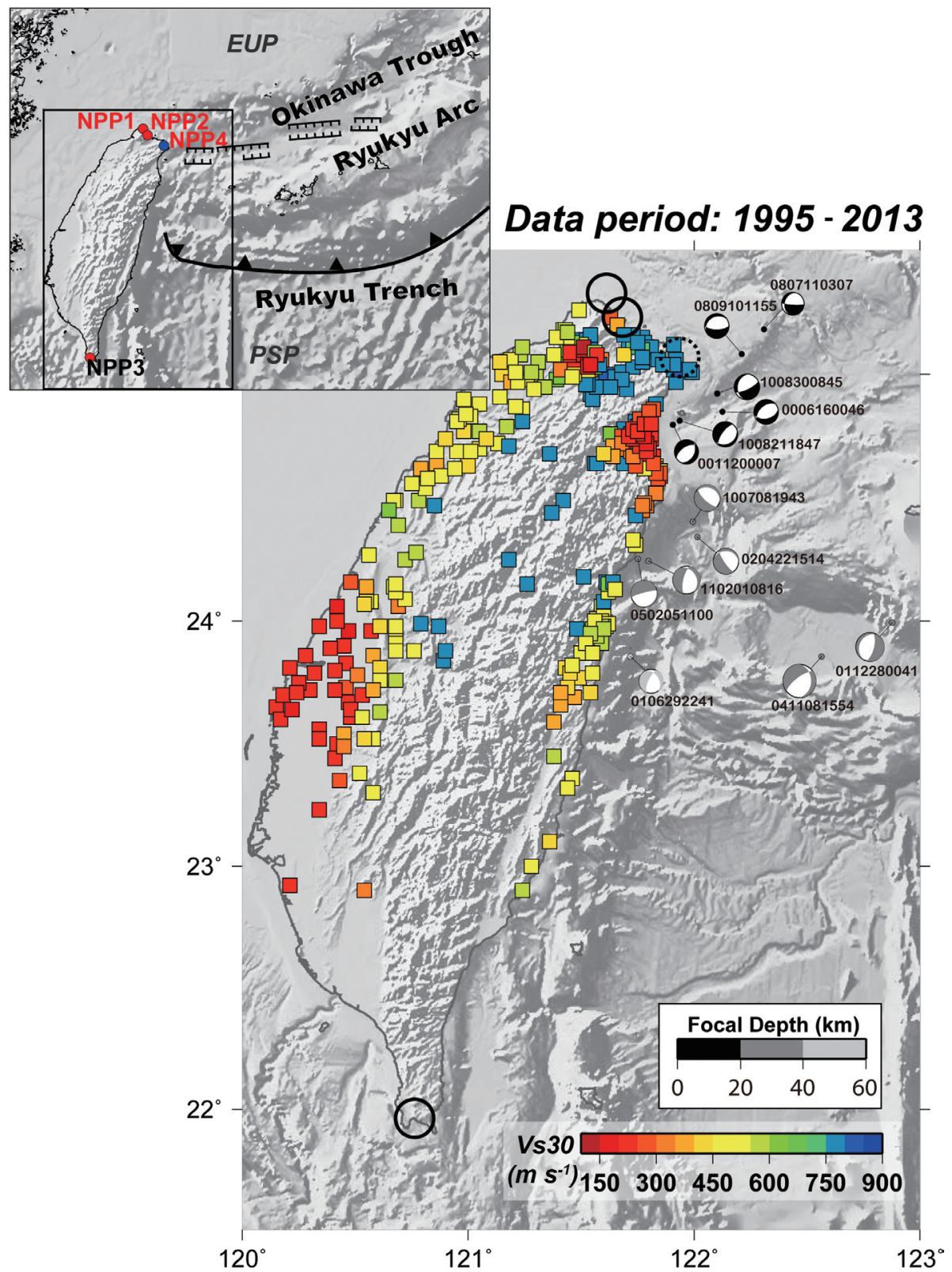

Fig. 1. Tectonic environment of Taiwan (left panel) and the distribution of 13 normal-faulting earthquakes and Taiwan Strong Motion Instrumentation Program (TSMIP) stations used in this study (right panel). Left panel: Taiwan is located at the collision boundary between the Philippine Sea Plate (PSP) and Eurasian Plate (EUP). Three nuclear power plant sites (squares) are located in Northern Taiwan (red: in operation; blue: under construction). Right panel: The location of the 13 analyzed normal-faulting earthquakes with their focal mechanisms. The color of the beach balls indicates the focal depth. The ID of events shown nearby the beach ball includes the original time of earthquakes; for instance, the ID 0809101155 indicates that the earthquake occurred at 11:55 on the 10 September 2008. The location of the TSMIP stations used in this study is indicated by squares with the color indicating the Vs30 of the sites. (Color online only) 
solutions, particularly those offshore, which had poor station coverage before.

We sorted through normal-faulting events occurring offshore northeast Taiwan using data between 1995 - 2013. Normal-faulting events were defined as events with rake angles between -60 and $-90^{\circ}$ according to the BATS solution. Because our focus was on events that can cause damage, only earthquakes with $\mathrm{M}_{\mathrm{w}} \geq 4$ that were recorded by at least 20 TSMIP stations were used. A total of 13 events corresponded to our criteria (Fig. 1, Table 1). The hypocentral distances of the observed events were between $20-300 \mathrm{~km}$ (Fig. 2a). The $\mathrm{M}_{\mathrm{w}}$ of 12 events is concentrated between 4.0 - 5.1. One event had $\mathrm{M}_{\mathrm{w}}$ of 5.9. Most events occurred at depths less than $30 \mathrm{~km}$ (Fig. 2b).

Strong-ground motion data must be appropriately processed to estimate real ground shaking from strong-ground motion events. We processed the data using the procedures stated in Fig. 3, following the data processing criteria of
NGA models (Darragh et al. 2004). The critical issue for data processing is removing long-period noise in the recordings, which typically involves using both low-cut filters and baseline correction together (Boore and Bommer 2005). The baseline was corrected after removing the instrument response in each ground motion record. The high-pass filtering band on each acceleration seismic waveform was determined by examining the amplitude ratio of signal to noise (RSN) in its respective displacement waveform. The signal amplitude was evaluated by averaging the absolute amplitude in the displacement waveform within a 10 -s time window starting from P-arrival. The noise amplitude was estimated with a $10-\mathrm{s}$ time-window before P-arrival. We developed an automatic procedure for determining the high-pass filtering band which promoted the RSN reaching the threshold value, 14, by trying consecutively the high-pass filtering band with incrementally increasing the frequency of $0.01 \mathrm{~Hz}$. After the baseline correction and high pass filter were completed, we

Table 1. Source parameters of 13 normal-faulting earthquakes used in this study.

\begin{tabular}{cccccc}
\hline Original Time & Longitude $\left({ }^{\circ} \mathbf{E}\right)$ & Latitude $\left({ }^{\circ} \mathbf{N}\right)$ & Strike/Dip/Rake & $\mathbf{M}_{w}$ & Focal Depth $(\mathbf{k m})$ \\
\hline 2000.06 .16 .0046 & 122.13 & 24.84 & $76 / 45 /-71$ & 4.4 & 17 \\
2000.11 .20 .0007 & 121.90 & 24.79 & $237 / 57 /-75$ & 4.4 & 17 \\
2001.06 .29 .2241 & 121.71 & 23.88 & $205 / 69 /-60$ & 4.2 & 45 \\
2001.12 .28 .0041 & 122.89 & 23.98 & $209 / 23 /-77$ & 5.1 & 20 \\
2002.04 .22 .1514 & 122.01 & 24.33 & $146 / 78 /-74$ & 4.5 & 27 \\
2004.11 .08 .1554 & 122.58 & 23.85 & $233 / 72 /-66$ & 5.9 & 21 \\
2005.02 .05 .1100 & 121.75 & 24.24 & $255 / 82 /-86$ & 4.8 & 20 \\
2008.07 .11 .0307 & 122.32 & 25.18 & $93 / 83 /-65$ & 4.0 & 11 \\
2008.09 .10 .1155 & 122.22 & 25.08 & $90 / 67 /-79$ & 4.4 & 13 \\
2010.07 .08 .1943 & 122.00 & 24.40 & $133 / 70 /-82$ & 4.7 & 24 \\
2010.08 .21 .1847 & 121.94 & 24.81 & $62 / 23 /-66$ & 4.5 & 18 \\
2011.08 .30 .0845 & 122.11 & 24.92 & $64 / 74 /-69$ & 4.6 & 11 \\
2011.02 .01 .0816 & 121.80 & 24.24 & $194 / 69 /-71$ & 4.9 & 23 \\
\hline
\end{tabular}
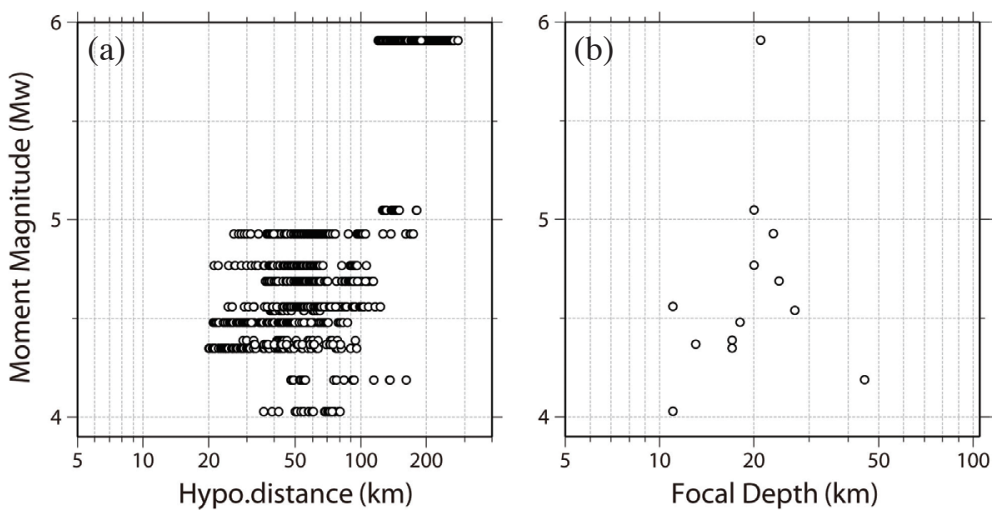

Fig. 2. Distribution of the $M_{w}$, hypocentral distance, and focal depth of the earthquakes analyzed in this study. (a) Distribution of the $M_{w}$ versus hypocentral distance of 13 normal-faulting events. (b) Distribution of the $\mathrm{M}_{\mathrm{w}}$ versus focal depth of 13 normal-faulting events. 


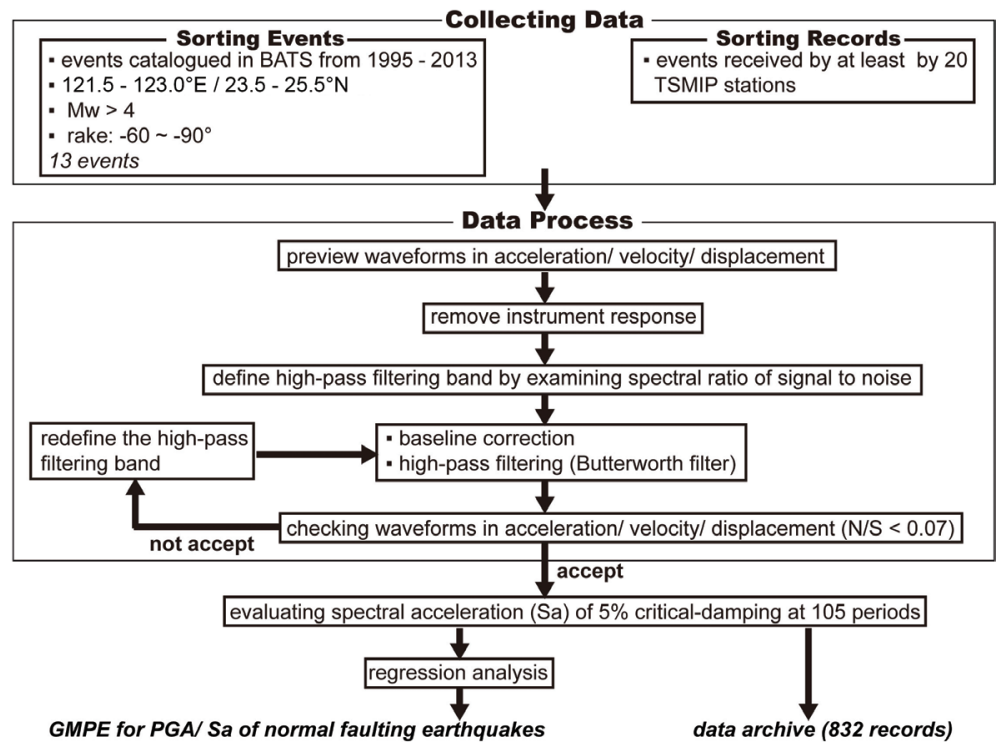

Fig. 3. Flowchart of the data processed for the strong ground motion records.

screened the processed data to confirm that the quality satisfied our requirement. We obtained 832 records from 13 events. Figure 4 shows the number of available data sets at 105 periods, ranging from $0.01-10 \mathrm{~s}$. Less data remained in the long period considering the filter frequency band. Less than 400 records were eligible regarding the period above $3 \mathrm{~s}$. With the processed waveform data, the geometric mean of two horizontal components was adopted to assess the PGA and $\mathrm{Sa}$ of horizontal ground-motion values.

For a given earthquake motion a single-degree-of-freedom system yields unique responses for various natural periods and damping ratios. Each response spectrum value is the maximum response of a single degree of freedom oscillator with a particular damping value for a particular period. We adopted a 5\% critical-damping ratio with 105 periods to calculate the response spectrum for a given earthquake waveform. Figure 5 shows four examples of estimated $\mathrm{Sa}$ regarding the hypocentral distance and shear-wave velocity of the sites within 30-m depth (Vs30). The Sa of station TAP069 nearby the source exhibited a higher value than that of station HWA057 at a far distance with the same site condition $\left(\mathrm{Vs} 30=760 \mathrm{~m} \mathrm{~s}^{-1}\right)$. For the period shorter than $0.2 \mathrm{~s}$, Sa was dominated by the site conditions more than by the hypocentral distance. For instance, the Sa at a soft-sediment site (e.g., ILA062) exhibited more intense ground shaking than that at a rock site (e.g., TAP069), whereas the Sa for longer periods was reciprocally influenced by the site condition and distance.

\section{FUNCTIONAL FORM OF ATTENUATION MODEL}

A ground-motion attenuation model describes the seis- mic energy decay related to the earthquake source, seismic wave propagation and site effect. The general form of an attenuation model (Joyner and Boore 1981) can be expressed as follows:

$y=b_{1} f_{1}(M) f_{2}(R) f_{3}(M, R) f_{4}(P) \varepsilon$

where $y$ is the ground motion value and $b_{1}$ is a constant. The functions $f_{1}(M), f_{2}(R), f_{3}(M, R)$, and $f_{4}(P)$ are related to the magnitude $M$, distance $R$, magnitude and distance $(M, R)$, and site effect $P$, respectively. The parameter $\varepsilon$ is the random ground motion error. Generally, the $f_{1}(M)$ is used as an exponential function of magnitude (Richter 1958) and expressed as follows:

$f_{1}(M)=e^{b_{2} M}$

The form of the function $f_{2}(R)$ can be presented as follows:

$f_{2}(R)=e^{b_{4} R}(R+b)^{-b_{3}}$

where $(R+b)^{-b_{3}}$ is induced by geometric spreading and $e^{b_{4} R}$ is related to the inelastic attenuation. The function of $f_{3}(M, R)$ expresses the attenuation uncertainty of the ground motion increasing with distance for various magnitudes of earthquakes (Campbell 1981) and is expressed as follows:

$f_{3}(M, R)=\left(R+b_{5} M^{b_{6}}\right)^{-b_{3}}$

The final function of $f_{4}(P)$ expresses the site effect 
contributing to the ground motion and is defined as an exponential function of Vs30 as follows:

$f_{4}(P)=e^{b_{7} V_{30}}$

The logarithmic form of Eq. (1) is presented as follows:

$$
\begin{aligned}
\ln y= & b_{1}+\ln \left[f_{1}(M)\right]+\ln \left[f_{2}(R)\right] \\
& +\ln \left[f_{3}(M, R)\right]+\ln \left[f_{4}(P)\right]+\ln \varepsilon
\end{aligned}
$$

Based on the attenuation form of Eq. (6), Lin et al. (2012) constructed a local GMPE using ample subduction-zone earthquake data in northeast Taiwan. The attenuation model describing the ground motion is presented as follows:

$$
\begin{aligned}
\ln \left(P G A_{i j} \text { or } S a_{i j}\right)= & C_{1}+C_{2} M_{i}+C_{3} \ln \left(R_{i j}+C_{4} e^{C_{5} M_{i}}\right) \\
& +C_{6} H_{i}+C_{8} Z t \\
& +C_{7}\left(V_{s 30} / 1130\right)+\ln \varepsilon
\end{aligned}
$$

where $i$ denotes the $i$ th earthquake and $j$ denotes the $j$ th station; $i j$ denotes the Sa or PGA values for $i$ th earthquake received by the $j$ th station. $M$ is the $\mathrm{M}_{\mathrm{w}}, R$ is the hypocentral distance $(\mathrm{km})$, and $H$ is the focal depth $(\mathrm{km}) . Z t$ indicates the earthquake type ( $Z t=0$ for interface earthquake; $Z t=1$ for intraplate earthquake), and $\ln \varepsilon$ is a random error.

The focal depth of most events used in this study was less than $30 \mathrm{~km}$; therefore, the events can be treated as interface earthquakes (Lin and Lee 2008). With $Z t=0$, Eq. (7) is compressed into the following equation:

$$
\begin{aligned}
\ln \left(P G A_{i j} \text { or } S a_{i j}\right)= & C_{1}+C_{2} M_{i}+C_{3} \ln \left(R_{i j}+C_{4} e^{C_{5} M_{i}}\right) \\
& +C_{6} H_{i}+C_{7}\left(V_{s 30} / 1130\right)+\ln \varepsilon
\end{aligned}
$$

We adopted Eq. (8) to estimate the constant $C_{1}$ and coefficients $C_{2}-C_{7}$ for normal-faulting earthquakes in offshore northeast Taiwan. In addition, we adopted the Vs30 of each station, which was obtained either from the PS logging data at or near the station, from Lee and Tsai (2008).

\section{REGRESSION ANALYSIS AND RESIDUALS}

A nonlinear regression was adopted to evaluate the empirical equation for the prediction of PGA and $\mathrm{Sa}$. We used the nonlinear regression algorithm of Seber and Wild (2003) to obtain the coefficients $C_{1}-C_{7}$ of Eq. (8) for the PGA and $\mathrm{Sa}$ at various periods. In the regression analysis the coefficients of $C_{4}, C_{5}$, and $C_{6}$ are quite consistent with the values of $0.5155,0.6325$, and 0.0075 , respectively, for various periods. Thus, $C_{4}, C_{5}$, and $C_{6}$ were considered as constants to avert the trade-off behavior between the related coefficients in the regression. The resulting coefficients for the PGA and Sa of 105 periods with their respective standard deviations are summarized in Table A1, Appendix A.

The PGA and Sa decimal logarithm residual values were calculated. The standard deviation for the regression model is

$\sigma_{\ln \varepsilon}=\sqrt{\frac{\sum_{i=1}^{n}\left\{\left[\ln (\text { predicted })_{i}\right]-\left[\ln (\text { observed })_{i}\right]\right\}^{2}}{n-1}}$

which is a general form representing the regression error (Kenney and Keeping 1954). The standard deviation of our resultant attenuation model for the PGA and Sa of 105 periods was between $0.5-0.8$. The regression for Sa exhibited a smaller error in shorter periods than it did in longer

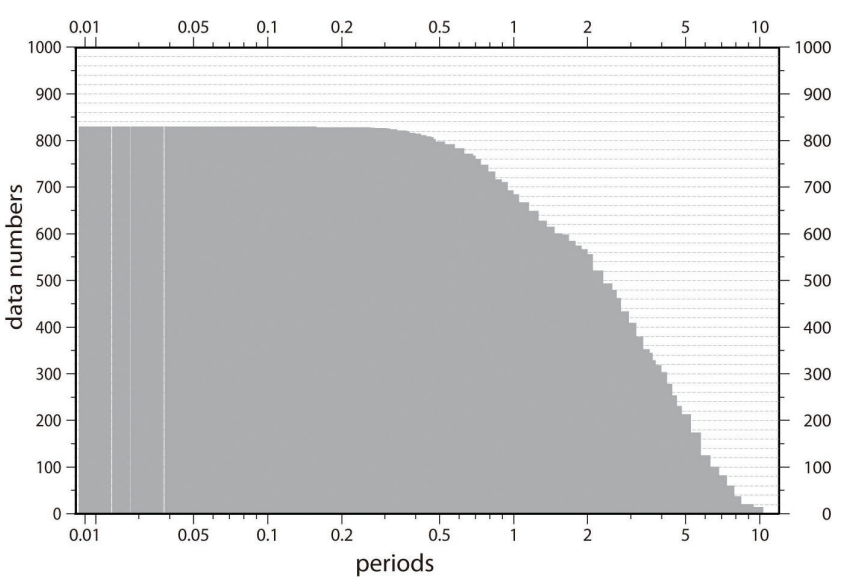

Fig. 4. Histogram of the number of data sets analyzed in this study at various periods.

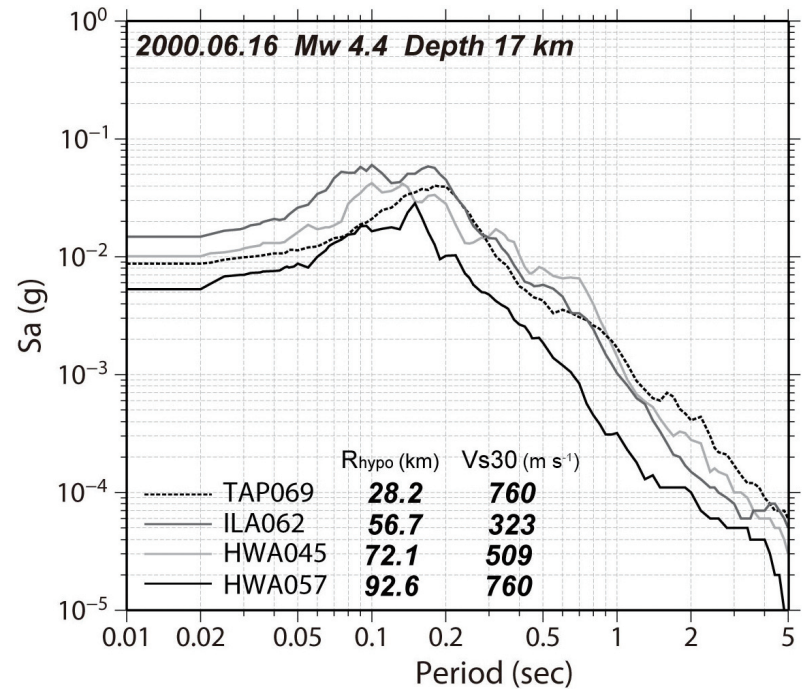

Fig. 5. Four examples of pseudo-spectral acceleration (Sa) in terms of different Vs30 and hypocentral distance. 
periods which has limited available records. Figure 6 shows the residuals of the PGA decimal logarithm between the observation and prediction. A normal distribution with a standard deviation $\sigma$ of Eq. (8) is 0.61 (Fig. 6a). In addition, the model residuals of Eq. (8) were plotted as functions of $\mathrm{M}_{\mathrm{w}}$, Vs30, depth, and hypocentral distance. There were no obvious biases regarding $M_{w}$, Vs30, depth, and hypocentral distance (Figs. 6b - e).

To compare the predicted $\mathrm{Sa}$ at various periods for our resulting attenuation model and the model of Lin et al. (2012), we showed the variation of the coefficients $C_{1}$, $C_{2}, C_{3}$, and $C_{7}$ of the two models together with the periods (Fig. 7). The comparison reveals that $C_{1}$ of our resulting equation increased until a period of $0.1 \mathrm{~s}$ and subsequently decreased with increasing periods, similar to the values estimated by Lin et al. (2012). The coefficients $C_{2}$ and $C_{3}$, referring to the $\mathrm{M}_{\mathrm{w}}$ and the hypocentral distance, both exhibit higher values in longer periods. In our model, $C_{3}$ exhibits a prominent minimal value at a period of $0.07 \mathrm{~s}$ and a maximal value between $0.6-0.9 \mathrm{~s}$. The $C_{3}$ variation in our equation is more prominent than that in Lin's equation. The coefficient $C_{7}$ refers to site conditions, Vs30 has almost an equivalent value in both equations for periods shorter than $0.3 \mathrm{~s}$. In periods longer than $0.3 \mathrm{~s}$, the lower $C_{7}$ obtained using our model indicates a higher reduction for $\mathrm{Sa}$ in longer periods.

\section{RESULTS}

We calculated the Sa of each record for normal-faulting events in offshore northeast Taiwan and estimated the respective GMPEs for PGA and Sa with 105 periods. The resulting attenuation model for PGA and $\mathrm{Sa}$ in periods of 0.2 , 1.0 , and $3.0 \mathrm{~s}$ is shown in Fig. 8 with observed data for the event $201102010816\left(\mathrm{M}_{\mathrm{w}}: 4.9\right.$, depth: $\left.23 \mathrm{~km}\right)$. The Vs30 of the stations recording this event was between $150-900 \mathrm{~m} \mathrm{~s}^{-1}$. Most of the observed data was consistent with one standard deviation of our predicted curve (black lines), suggesting that our GMPEs exhibited satisfying correspondence to the observed data. The comparison of observed PGA and Sa for normal-faulting earthquakes with two attenuation models indicated that the observed PGA and Sa were more consistent with the new resultant attenuation model for normalfaulting earthquakes than they were with the GMPE of Lin et al. (2012). A higher Sa but lower PGA of normal-faulting events than the GMPE for interplate earthquakes of Lin et al. (2012) was revealed. The following discusses the detailed Sa and PGA characteristics predicted by the attenuation model for normal-faulting earthquakes and compares the predicted values from other attenuation models obtained in other regions.

\subsection{Spectral Pseudo Acceleration}

The estimated Sa for $\mathrm{M}_{\mathrm{w}} 5.0$ is shown in Fig. 9. Overall, the Sa at soft sites (Vs30 $\left.=150 \mathrm{~m} \mathrm{~s}^{-1}\right)($ Fig. 9a) was higher than that at hard sites (Vs30 $=760 \mathrm{~m} \mathrm{~s}^{-1}$ ) (Fig. 9b). We compared the estimated $\mathrm{Sa}$ at a high frequency to the predicted PGA in terms of that $\mathrm{Sa}$ at a high frequency should be close to the PGA value to validate the Sa attenuation model. The $\mathrm{Sa}$ assessment of our resulting model at $0.01 \mathrm{~s}(\mathrm{Sa}[0.01])$ was close to the predicted PGA value (black triangle). The deviation between the Sa [0.01] and the PGA was approximately $0.003 \mathrm{~g}$. The assessed Sa for normal-faulting events in offshore northeast Taiwan was higher than that of Lin (2009) for crustal normal-faulting earthquakes and the model of Lin et al. (2012) for interplate earthquakes. Our predicted model for Sa together with the whole period was closer to the models developed by Boore and Atkinson (2008) for non-specific crustal event fault types or for normal-faulting earthquakes. The predicted Sa of our model, the model of Lin (2009) for normal-faulting earthquakes, and the models of Boore and Atkinson (2008) for non-specific faulting types and normalfaulting events are consistent for periods longer than $3 \mathrm{~s}$.

Figure 10 shows the normalized $\mathrm{Sa}$ (the ratio of $\mathrm{Sa}$ to PGA) with an $\mathrm{M}_{\mathrm{w}}$ of 4 to 6 at hypocentral distances of 50 and $150 \mathrm{~km}$ (Figs. 10a and b). As shown in Fig. 10, the normalized Sa for small earthquakes (e.g., $\mathrm{M}_{\mathrm{w}} 4$ and 5) have maximal values in periods of approximately $0.2 \mathrm{~s}$. For larger earthquakes (e.g., $\mathrm{M}_{\mathrm{w}}$ 6), the maximal normalized $\mathrm{Sa}$ is in longer periods. The higher $\mathrm{Sa}$ at longer periods is more significant at $150 \mathrm{~km}$ (Fig. 10b) than at $50 \mathrm{~km}$ (Fig. 10a). Because of the prominent surface waves that larger earthquakes can generate and the longer distance the surface waves can travel, the observation indicates that the maximal Sa for larger earthquakes is dominated by the surface waves. The effect was prominent for distances between $100-200 \mathrm{~km}$.

\subsection{PGA}

We compared our resultant model with several other models (Si and Midorikawa 2000; Boore and Atkinson 2008; Lin 2009; Lin et al. 2012) for interplate and crustal events with the observed data to characterize the PGA of normal-faulting earthquakes offshore northeast Taiwan (Fig. 11). We present six examples of the comparison in Fig. 11. Figures $11 \mathrm{a}-\mathrm{c}$ show the predicted models for three normal-faulting events with $\mathrm{M}_{\mathrm{w}}$ of 4.4 to 4.8 analyzed in this study. Figures $11 \mathrm{e}$ and $\mathrm{f}$ show the predicted models for two normal-faulting events with $\mathrm{M}_{\mathrm{w}}$ of 5.1 and 5.7, which were archived in the NGA flat-file, occurred in the United States (NGA0088 at Borah Peak Central Idaho; NGA0152 in southwest Nevada). The event $\left(M_{w} 4.1\right)$ shown in Fig. 11d was excluded from the regression analysis, because less than 20 records referred to it. We delineated the predicted PGA curves of this event to examine the correspondence of our resulting equation with the observed data. The predicted curves in Figs. 11a - d and e $-\mathrm{f}$ are depicted with Vs30 = 500 and $700 \mathrm{~m} \mathrm{~s}^{-1}$, which are the mean Vs30 of the observed 

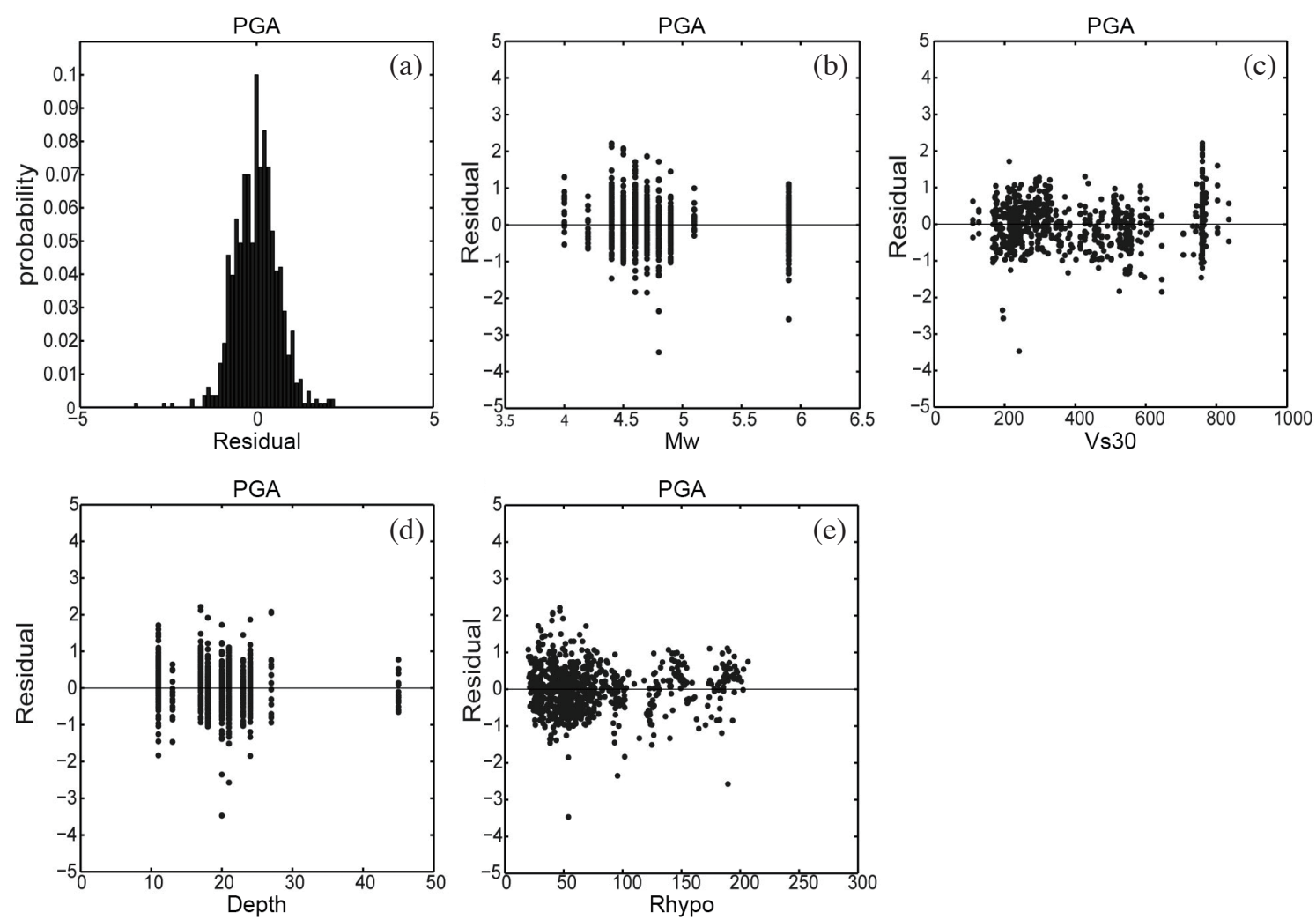

Fig. 6. (a) Residual distribution for PGA, and the distribution of residuals plotted against (b) $\mathrm{M}_{\mathrm{w}}$; (c) Vs30; (d) focal depth; and (e) hypocentral distance.

$$
\ln (P G A \text { or } \mathrm{Sa})=C_{1}+C_{2} M w+C_{3} \ln \left(R_{\text {hypo }}+0.5155 e^{0.63255 M w}\right)+0.0075 H_{i}+C_{7} * \ln (V s 30 / 1130)
$$
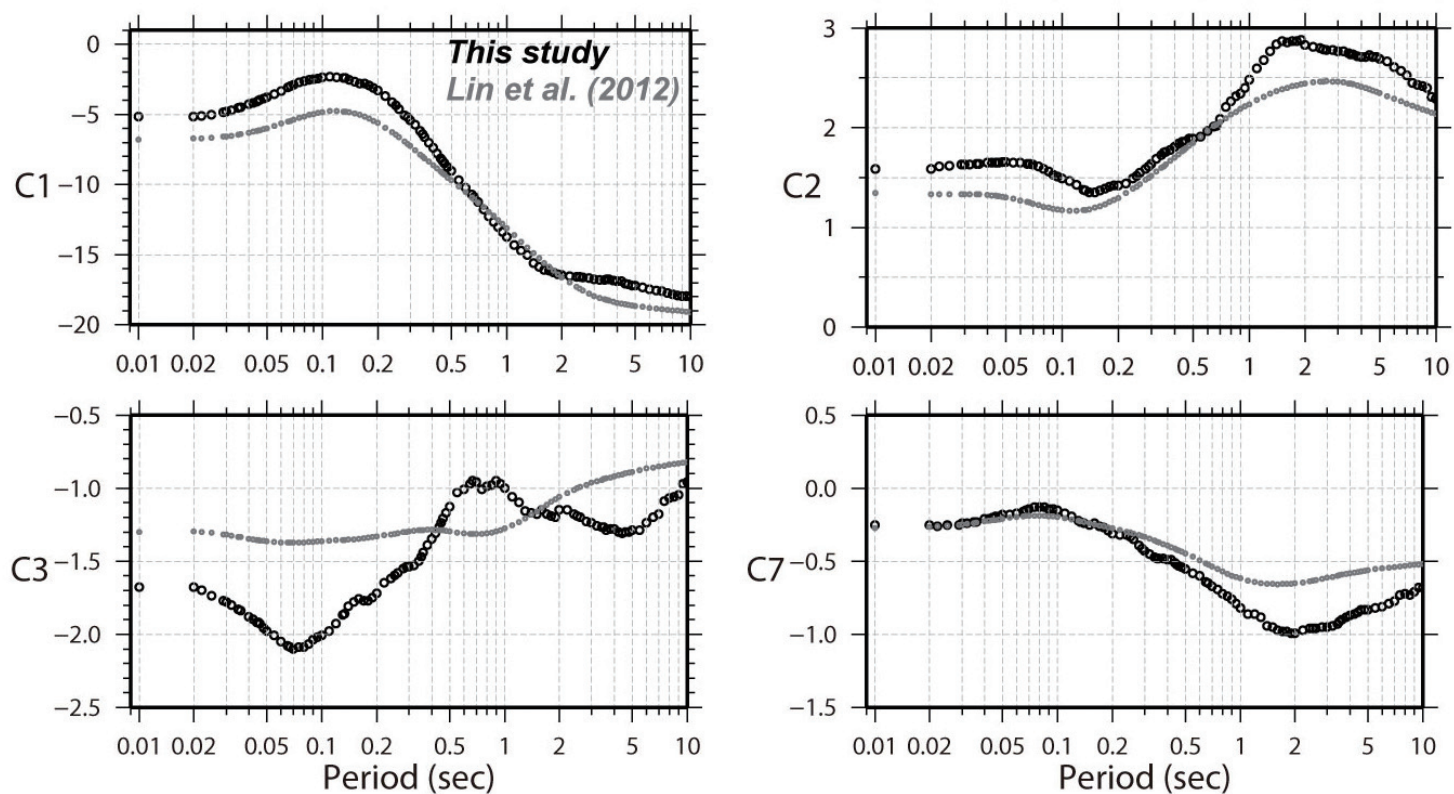

Fig. 7. Variation in coefficients of equations for Sa with various periods. The black and gray circles indicate the value of the coefficients for normalfaulting earthquakes (this study) and interplate earthquakes (Lin et al. 2012), respectively. 


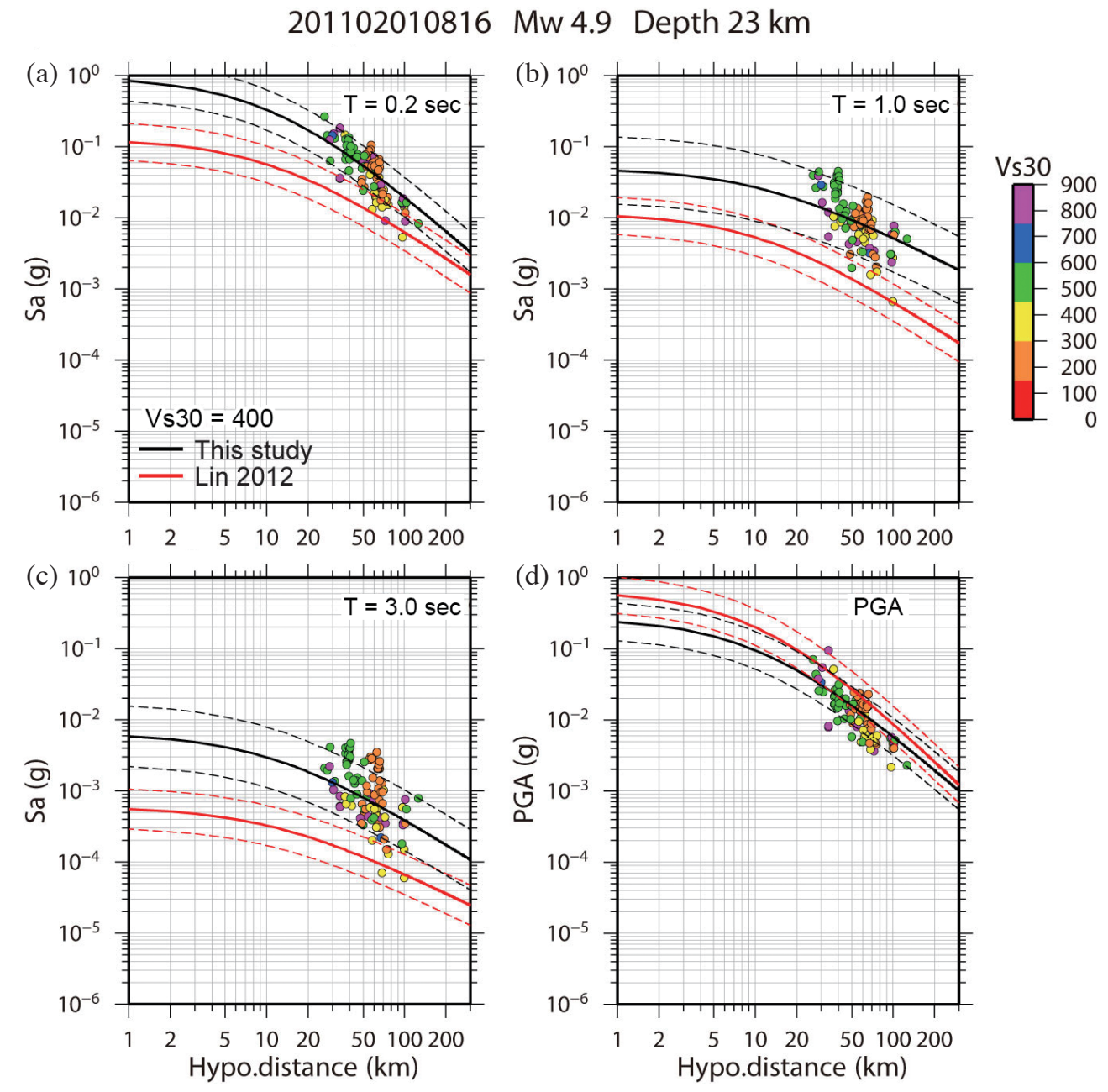

Fig. 8. Comparison of the attenuation model developed in this study with the model of Lin et al. (2012) for Sa in the periods (a) $0.2 \mathrm{~s}$; (b) $1.0 \mathrm{~s}$; (c) $3.0 \mathrm{~s}$; and (d) PGA together with the observed data of an $\mathrm{M}_{\mathrm{w}} 4.9$ normal-faulting earthquake. The solid lines are the median of the models and the dashed lines are curves for one standard deviation with the median. The lines in black and red denote the model of this study and the model of Lin et al. (2012), respectively. The color of the dots denotes the Vs30 of the receiving site. (Color online only)
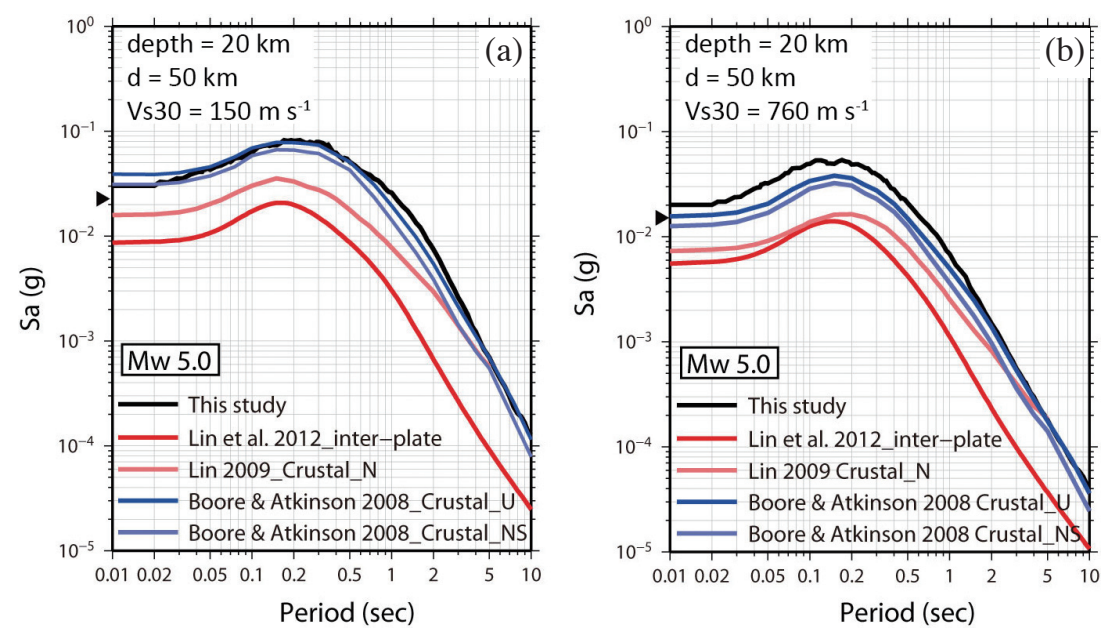

Fig. 9. Spectral acceleration with various Vs 30 at a focal depth of $20 \mathrm{~km}$ and a hypocentral distance of $50 \mathrm{~km}$ for various models. (a) Vs $30=150 \mathrm{~m} \mathrm{~s}{ }^{-1}$; (b) Vs30 $=760 \mathrm{~m} \mathrm{~s}^{-1}$. The spectral shape in black is the attenuation model obtained in this study for normal-faulting events in offshore northeast Taiwan. The spectral shapes in red and pink denote the attenuation model for interplate earthquakes (Lin et al. 2012) and crustal normal-faulting events (Lin 2009) of Taiwan, respectively. The spectral shapes in blue and shallow blue denote the curves estimated using the model of Boore and Atkinson (2008) for unspecific faulting types of crustal events and crustal normal-faulting events, respectively. (Color online only) 

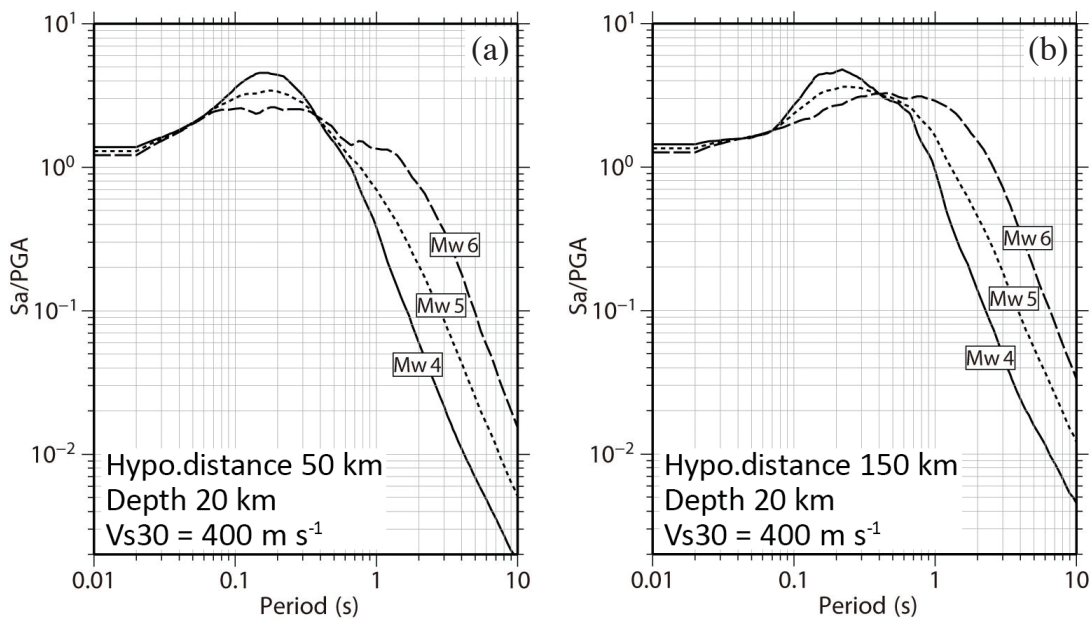

Fig. 10. Variation of normalized spectral pseudo acceleration (Sa) for $\mathrm{M}_{\mathrm{w}}$ of 4 to 6 with $\mathrm{Vs} 30=400 \mathrm{~m} \mathrm{~s}^{-1}$ at a hypocentral distance of (a) $50 \mathrm{~km}$ and (b) $150 \mathrm{~km}$
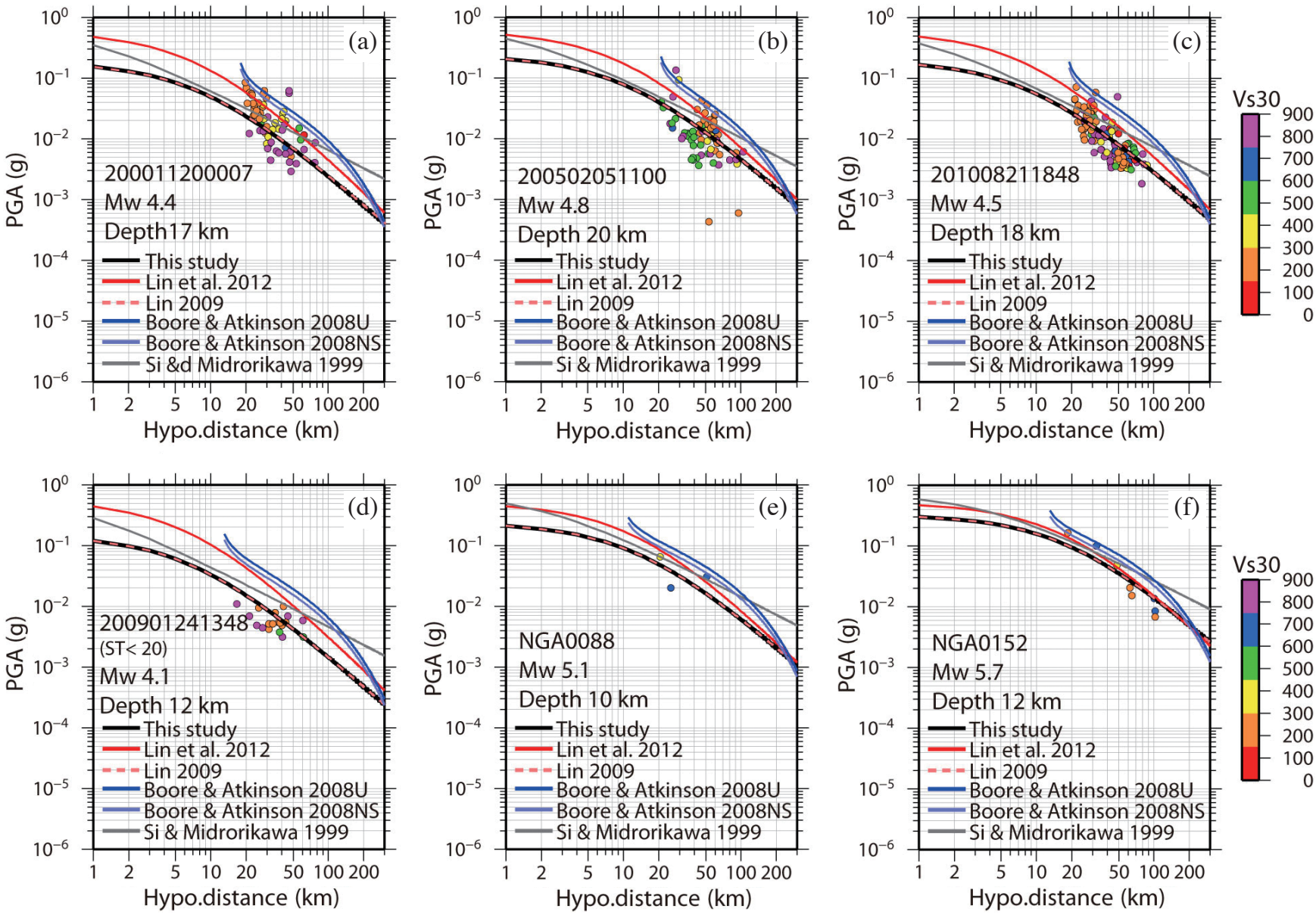

Fig. 11. Comparison of the PGA attenuation curves of this study and those of other studies for six examples. (a), (b), (c), and (d) are examples for observed normal-faulting data of the Taiwan Strong Ground Motion, and (e) and (f) are examples for normal-faulting data archived in the NGA flatfile. The black line is the curve of the model developed in this study. The red solid and pink dashed lines are the curves for interplate earthquakes (Lin et al. 2012) and for crustal normal-faulting earthquakes (Lin 2009), respectively. The deep blue and shallow blue curves are models of Boore and Atkinson (2008) for crustal unspecified fault types and normal-faulting earthquakes, respectively. The gray line is the curve of model of Si and Midorikawa (2000) for Japanese crustal events. (Color online only) 
data, respectively. Overall, our model describes the observed data adequately, even for the normal-faulting data which was not involved in the regression analysis (Figs. 11d - f). The comparison reveals that our resulting model for the PGA of normal-faulting events was consistent with the model of Lin (2009) for crustal normal-faulting events, but yielded lower values than the models of Lin et al. (2012) for interplate earthquakes, Boore and Atkinson (2008) for crustal unspecified fault types and normal-faulting earthquakes, and Si and Midorikawa (2000) for crustal events. It indicates that the PGA value of normal-faulting earthquakes in offshore northeast Taiwan is lower than that of interplate earthquakes in the Taiwan subduction zone and that of active crust events in other regions. The PGA value of normal-faulting events in the offshore northeast Taiwan is more consistent with the value for the Taiwan crustal normal-faulting earthquakes.

\section{DISCUSSION}

GMPEs as empirical relationships predicting ground shaking have been widely studied and used in earthquake engineering. The equations differ mainly in the algebraic form used to describe various parameters in relation to the ground motion, and the choice of data that developers use for derivation. Equations for normal-faulting earthquakes are seldom investigated. The main reason is that normal-faulting earthquakes are commonly considered to exhibit less intense ground shaking, causing less damage than thrust or strikeslip earthquakes. An additional reason may be attributable to the limited available data for normal-faulting earthquakes.

Our study examined the ground motion of normalfaulting events in offshore northeast Taiwan and extended the usage of GMPEs for normal-faulting earthquakes to moderate events, which has been scarcely performed in Taiwan. The analysis revealed that the PGA of normal-faulting earthquakes is lower than that predicted using GMPEs that emphasize thrust or strike-slip events, corresponding to the general understanding that normal-faulting earthquakes have less intense ground shaking. By contrast, the Sa of these normal-faulting earthquakes is higher than that obtained through the estimation of generally used equations.

Normal-faulting earthquakes generally generate smaller ground accelerations than do thrust or strike-slip events. McGarr (1984) and several independent analyses (e.g., Brune 1970; Hanks and Johnson 1976; McGarr 1981; Spudich et al. 1999) have indicated that the horizontal PGA could be related to local stress drops in the seismic source region which reflects the crustal strength. As evaluated by McGarr (1984), the crustal strength in an extensional region is approximately one third of that in a compressional region. The Ryukyu Arc and Okinawa Trough, where the analyzed normal-faulting earthquakes occurred, are considered typical extensional tectonic environments (Shinjo 1999; Lin et al. 2004, 2007). By contrast, the source region where the normal-faulting Fukushima earthquake and its related normal-faulting sequence occurred was considered a typical E-W compressional environment (Kubo et al. 2002; Townend and Zoback 2006) before the 2011 Tohoku earthquake $\left(\mathrm{M}_{\mathrm{w}}\right.$ 9.0). The normalfaulting earthquakes occurred because of a significant reduction in trench-normal compressional stress after the Tohoku earthquake (Kato et al. 2011; Imanishi et al. 2012). This implies that the inherent compressional tectonic environment may be responsible for the high PGA observed in the Fukushima normal-faulting earthquake.

Adopting a unique perspective, Westaway and Smith (1989) studied worldwide normal-faulting events with magnitudes from 4 - 7.5 and observed that normal-faulting earthquakes with magnitudes exceeding 5 caused ground accelerations equivalent to those in reverse-faulting and strike-slip events. This observation contradicts the widely held view that normal-faulting earthquakes generate lower ground accelerations than other faulting types of event. Figure 11 shows a comparison of six models for interplate and crustal events of normal-faulting or nonspecific fault types. The discrepancy of the predicted PGA between normal-faulting events and interplate or crustal events with $\mathrm{M}_{\mathrm{w}}$ of 4 to 5 is larger than that of events with $\mathrm{M}_{\mathrm{w}}$ exceeding 5 . This seems to imply that the PGA of greater normal-faulting earthquakes is comparable to those of thrust or strike-slip events. However, the limited available data regarding normal-faulting events with $\mathrm{M}_{\mathrm{w}}$ exceeding 6 constrains our verification.

\section{CONCLUSION}

GMPEs have been widely used and studied to predict ground shaking for earthquake engineering. By contrast, prediction equations for normal-faulting earthquakes have been little investigated because they have been considered less hazardous and limited data has been available. However moderately sized earthquakes can cause substantial damage (Lander 1973; Ates 1985). To assess the ground shaking impact of normal-faulting earthquakes in offshore northeast Taiwan on three NPPs (NPP-1, NPP-2, and NPP-4), we developed the GMPE for normal-faulting earthquakes with moderate to large sizes in offshore northeast Taiwan. The $M_{w}$ of most analyzed data was between 4 - 5. The resulting attenuation relationship reveals that normal-faulting earthquakes generate strong $\mathrm{Sa}$, which is not adopted in the attenuation equations commonly used in Taiwan. Regarding the PGA values, our analysis reveals lower values for normal-faulting earthquakes compared with those obtained using common GMPEs used mainly for thrust-faulting and strike-slip events in the subduction zone. This study examined the seismic risk caused by normal-faulting earthquakes from the extensional structure offshore northeast Taiwan, and extended the widely used empirical relationships for normal-faulting earthquakes. 
Acknowledgements We thank the Geophysical Database Management System (GDMS) of the Central Weather Bureau (CWB) for providing high quality data from the Taiwan Strong Motion Implementation Program (TSMIP). Comments and suggestions from the Editor and two Anonymous Reviewers greatly benefited and improved this manuscript. This work was conducted under support from the Institute of Nuclear Energy Research, Atomic Energy Council, Executive Yuan, Taiwan grant.

\section{REFERENCES}

Abrahamson, N. and W. Silva, 2008: Summary of the Abrahamson \& Silva NGA ground-motion relations. Earthq. Spectra, 24, 67-97, doi: 10.1193/1.2924360. [Link]

Abrahamson, N., W. J. Silva, and R. Kamai, 2013: Update of the AS08 ground-motion prediction equations based on the NGA-West2 data set. PEER Report 2013/04, Pacific Earthquake Engineering Research Center, Headquarters, University of California, Berkeley, $174 \mathrm{pp}$.

Abrahamson, N., N. Gregor, and K. Addo, 2015: BC Hydro ground motion prediction equations for subduction earthquakes. Earthq. Spectra, doi: 10.1193/051712EQS188MR. (in-press) [Link]

Ancheta, T. D., R. B. Darragh, J. P. Stewart, E. Seyhan, W. J. Silva, B. S. J. Chiou, K. E. Wooddell, R. W. Graves, A. R. Kottke, D. M. Boore, T. Kishida, and J. L. Donahue, 2014: NGA-West2 database. Earthq. Spectra, 30, 989-1005, doi: 10.1193/070913EQS197M. [Link]

Anderson, J. G., H. Kawase, G. P. Biasi, J. N. Brune, and S. Aoi, 2013: Ground motions in the Fukushima Hamadori, Japan, normal-faulting earthquake. Bull. Seismol. Soc. Am., 103, 1935-1951, doi: 10.1785/0120120252. [Link]

Ates, R., 1985: Turkish strong ground motion data acquisition and analysis. Phys. Earth Planet. Inter., 38, 123133, doi: 10.1016/0031-9201(85)90150-5. [Link]

Atkinson, G. M. and D. M. Boore, 2003: Empirical ground-motion relations for subduction-zone earthquakes and their application to Cascadia and other regions. Bull. Seismol. Soc. Am., 93, 1703-1729, doi: 10.1785/0120020156. [Link]

Boore, D. M. and J. J. Bommer, 2005: Processing of strongmotion accelerograms: Needs, options and consequences. Soil Dyn. Earthq. Eng., 25, 93-115, doi: 10.1016/j. soildyn.2004.10.007. [Link]

Boore, D. M. and G. M. Atkinson, 2008: Ground-motion prediction equations for the average horizontal component of PGA, PGV, and 5\%-damped PSA at spectral periods between $0.01 \mathrm{~s}$ and $10.0 \mathrm{~s}$. Earthq. Spectra, 24, 99-138, doi: 10.1193/1.2830434. [Link]

Brune, J. N., 1970: Tectonic stress and the spectra of seismic shear waves from earthquakes. J. Geophys. Res., 75, 4997-5009, doi: 10.1029/JB075i026p04997. [Link]
Brune, J. N., 2000: Precarious rock evidence for low ground shaking on the footwall of major normal faults. Bull. Seismol. Soc. Am., 90, 1107-1112, doi: 10.1785/0119990111. [Link]

Brune, J. N. and A. Anooshehpoor, 1999: Dynamic geometrical effects on strong ground motion in a normal fault model. J. Geophys. Res., 104, 809-815, doi: 10.1029/1998JB900030. [Link]

Campbell, K. W., 1981: Near-source attenuation of peak horizontal acceleration. Bull. Seismol. Soc. Am., 71, 2039-2070

Campbell, K. W., 1997: Empirical near-source attenuation relationships for horizontal and vertical components of peak ground acceleration, peak ground velocity, and pseudo-absolute acceleration response spectra. Seismol. Res. Lett., 68, 154-179, doi: 10.1785/gssrl.68.1.154. [Link]

Campbell, K. W. and Y. Bozorgnia, 2008: NGA ground motion model for the geometric mean horizontal component of PGA, PGV, PGD and 5\% damped linear elastic response spectra for periods ranging from 0.01 to $10 \mathrm{~s}$. Earthq. Spectra, 24, 139-171, doi: 10.1193/1.2857546. [Link]

Chang, T. Y., F. Cotton, and J. Angelier, 2001: Seismic attenuation and peak ground acceleration in Taiwan. Bull. Seismol. Soc. Am., 91, 1229-1246, doi: 10.1785/0120000729. [Link]

Chiou, B. S. J. and R. R. Youngs, 2008: An NGA model for the average horizontal component of peak ground motion and response spectra. Earthq. Spectra, 24, 173215, doi: 10.1193/1.2894832. [Link]

Darragh, B., W. Silva, and N. Gregor, 2004: Strong motion record processing for the PEER center. Proceedings of COSMOS Invited Workshop on Strong-Motion Record Processing, Richmond, Calif, USA, 26-27.

Hanks, T. C. and D. A. Johnson, 1976: Geophysical assessment of peak accelerations. Bull. Seismol. Soc. Am., 66, 959-968.

Imanishi, K., R. Ando, and Y. Kuwahara, 2012: Unusual shallow normal-faulting earthquake sequence in compressional northeast Japan activated after the 2011 off the Pacific coast of Tohoku earthquake. Geophys. Res. Lett., 39, L09306, doi: 10.1029/2012GL051491. [Link]

Joyner, W. B. and D. M. Boore, 1981: Peak horizontal acceleration and velocity from strong-motion records including records from the 1979 imperial valley, California, earthquake. Bull. Seismol. Soc. Am., 71, 20112038.

Kanno, T., A. Narita, N. Morikawa, H. Fujiwara, and Y. Fukushima, 2006: A new attenuation relation for strong ground motion in Japan based on recorded data. Bull. Seismol. Soc. Am., 96, 879-897, doi: 10.1785/0120050138. [Link] 
Kato, A., S. Sakai, and K. Obara, 2011: A normal-faulting seismic sequence triggered by the 2011 off the Pacific coast of Tohoku earthquake: Wholesale stress regime changes in the upper plate. Earth Planets Space, 63, 745-748, doi: 10.5047/eps.2011.06.014. [Link]

Kenney, J. F. and E. S. Keeping, 1954: Mathematics of Statistics, Part One, $3^{\text {rd }}$ edtion, Van Nostrand, New York, 77-80.

Kubo, A., E. Fukuyama, H. Kawai, and K. Nonomura, 2002: NIED seismic moment tensor catalogue for regional earthquakes around Japan: Quality test and application. Tectonophysics, 356, 23-48, doi: 10.1016/ S0040-1951(02)00375-X. [Link]

Lander, J. F., 1973: Seismological notes--May and June 1972. Bull. Seismol. Soc. Am., 63, 335-338.

Lee, C. T. and B. R. Tsai, 2008: Mapping Vs30 in Taiwan. Terr. Atmos. Ocean. Sci., 19, 671-682, doi: 10.3319/ TAO.2008.19.6.671(PT). [Link]

Lee, C. T., H. C. Chiu, P. S. Lin, and C. T. Cheng, 2009: Research on establishment and maintenance of strongmotion database and development of user platform II: The construction of strong motion database from Taiwan subduction zone earthquakes. Sinotech Engineering of Consultants, Inc. Research and Development Series, R-GT-09-03. (in Chinese)

Lin, J. Y., S. K. Hsu, and J. C. Sibuet, 2004: Melting features along the western Ryukyu slab edge (northeast Taiwan): Tomographic evidence. J. Geophys. Res., 109, B12402, doi: 10.1029/2004JB003260. [Link]

Lin, J. Y., J. C. Sibuet, C. S. Lee, S. K. Hsu, and F. Klingelhoefer, 2007: Origin of the southern Okinawa Trough volcanism from detailed seismic tomography. J. Geophys. Res., 112, B08308, doi: 10.1029/2006JB004703. [Link]

Lin, P. S., 2009: Ground-motion attenuation relationship and path-effect study using Taiwan data set. Ph.D. Thesis, National Central University, Taiwan. (in Chinese)

Lin, P. S. and C. T. Lee, 2008: Ground-motion attenuation relationships for subduction-zone earthquakes in northeastern Taiwan. Bull. Seismol. Soc. Am., 98, 220-240, doi: 10.178ß5/0120060002. [Link]

Lin, P. S., P. S. Hsie, Y. R. Lee, C. T. Cheng, and K. S. Shao, 2012: The research of probabilistic seismic hazard analysis and geological survey of nuclear power plant: Construction of ground motion prediction equation for response spectra. Commission Report of the Institute of Nuclear Energy Research, Atomic Energy Council, Executive Yuan. (in Chinese)

Liu, K. S. and Y. B. Tsai, 2005: Attenuation relationships of peak ground acceleration and velocity for crustal earthquakes in Taiwan. Bull. Seismol. Soc. Am., 95, 10451058, doi: 10.1785/0120040162. [Link]

McGarr, A., 1981: Analysis of peak ground motion in terms of a model of inhomogeneous faulting. J. Geophys.
Res., 86, 3901-3912, doi: 10.1029/JB086iB05p03901. [Link]

McGarr, A., 1984: Scaling of ground motion parameters, state of stress, and focal depth. J. Geophys. Res., 89, 6969-6979, doi: 10.1029/JB089iB08p06969. [Link]

Richter, C., 1958: Elementary Seismology, W. H. Freeman, San Francisco, California, 768 pp.

Seber, G. A. F. and C. J. Wild, 2003: Nonlinear Regression, John Wiley \& Sons, 768 pp.

Shi, B., J. N. Brune, Y. Zeng, and A. Anooshehpoor, 2003: Dynamics of earthquake normal faulting: two-dimensional lattice particle model. Bull. Seismol. Soc. Am., 93, 1179-1197, doi: 10.1785/0120000250. [Link]

Shinjo, R., 1999: Geochemistry of high Mg andesites and the tectonic evolution of the Okinawa Trough-Ryukyu arc system. Chem. Geol., 157, 69-88, doi: 10.1016/ S0009-2541(98)00199-5. [Link]

Si, H. and S. Midorikawa, 2000: New attenuation relations for peak ground acceleration and velocityconsidering effects of fault type and site condition. Proceedings of $12^{\text {th }}$ World Conference on Earthquake Engineering, No. 532 .

Si, H., T. Kawasato, M. Ohba, T. Watanabe, T. Masatsuki, and A. Sawaii, 2012: A comparison of existing ground motion prediction equation to normal faulting earthquake. Summaries of Technical Papers of Annual Meeting, Architectural Institute of Japan, B-2, 177-178.

Sibuet, J. C., B. Deffontaines, S. K. Hsu, N. Thareau, J. P. Le Formal, C. S. Liu, and ACT Party, 1998: Okinawa trough backarc basin: Early tectonic and magmatic evolution. J. Geophys. Res., 103, 30245-30267, doi: 10.1029/98JB01823. [Link]

Spudich, P., W. B. Joyner, A. G. Lindh, D. M. Boore, B. M. Margaris, and J. B. Fletcher, 1999: SEA99: A revised ground motion prediction relation for use in extensional tectonic regimes. Bull. Seismol. Soc. Am., 89, 1156-1170.

Toda, S. and H. Tsutsumi, 2013: Simultaneous reactivation of two, subparallel, inland normal faults during the $M_{\mathrm{w}} 6.6$ 11 April 2011 Iwaki earthquake triggered by the $M_{\mathrm{w}} 9.0$ Tohoku-oki, Japan, earthquake. Bull. Seismol. Soc. Am., 103, 1584-1602, doi: 10.1785/0120120281. [Link]

Townend, J. and M. D. Zoback, 2006: Stress, strain, and mountain building in central Japan. J. Geophys. Res., 111, B03411, doi: 10.1029/2005JB003759. [Link]

Westaway, R. and R. B. Smith, 1989: Strong ground motion in normal-faulting earthquakes. Geophys. J. Int., 96, 529-559, doi: 10.1111/j.1365-246X.1989.tb06012.x. [Link]

Wu, Y.M., T.C.Shin, and C. H.Chang, 2001: Near real-time mapping of peak ground acceleration and peak ground velocity following a strong earthquake. Bull. Seismol. Soc. Am., 91, 1218-1228, doi: 10.1785/0120000734. [Link] 
Appendix Table A1. Coefficients of the ground-motion model for PGA and Sa with their respective standard deviations.

\begin{tabular}{|c|c|c|c|c|c|c|c|c|}
\hline Parameter & $\mathrm{C}_{1}$ & $\mathrm{C}_{2}$ & $\mathrm{C}_{3}$ & $\mathrm{C}_{4}$ & $\mathrm{C}_{5}$ & $\mathrm{C}_{6}$ & $\mathbf{C}_{7}$ & $\sigma$ \\
\hline PGA & -5.60 & 1.63 & -1.70 & 0.51552 & 0.63255 & 0.0075 & -0.27 & 0.61 \\
\hline $\mathrm{Sa}[0.010]$ & -5.17 & 1.59 & -1.68 & 0.51552 & 0.63255 & 0.0075 & -0.25 & 0.59 \\
\hline $\mathrm{Sa}[0.020]$ & -5.17 & 1.59 & -1.68 & 0.51552 & 0.63255 & 0.0075 & -0.25 & 0.59 \\
\hline $\mathrm{Sa}[0.022]$ & -5.12 & 1.61 & -1.70 & 0.51552 & 0.63255 & 0.0075 & -0.26 & 0.60 \\
\hline $\mathrm{Sa}[0.025]$ & -5.00 & 1.62 & -1.74 & 0.51552 & 0.63255 & 0.0075 & -0.25 & 0.60 \\
\hline $\mathrm{Sa}[0.029]$ & -4.83 & 1.63 & -1.77 & 0.51552 & 0.63255 & 0.0075 & -0.25 & 0.61 \\
\hline $\mathrm{Sa}[0.030]$ & -4.78 & 1.63 & -1.78 & 0.51552 & 0.63255 & 0.0075 & -0.24 & 0.61 \\
\hline $\mathrm{Sa}[0.032]$ & -4.69 & 1.63 & -1.80 & 0.51552 & 0.63255 & 0.0075 & -0.24 & 0.62 \\
\hline $\mathrm{Sa}[0.035]$ & -4.53 & 1.64 & -1.83 & 0.51552 & 0.63255 & 0.0075 & -0.23 & 0.63 \\
\hline $\mathrm{Sa}[0.036]$ & -4.47 & 1.64 & -1.84 & 0.51552 & 0.63255 & 0.0075 & -0.23 & 0.64 \\
\hline $\mathrm{Sa}[0.040]$ & -4.27 & 1.65 & -1.88 & 0.51552 & 0.63255 & 0.0075 & -0.21 & 0.65 \\
\hline $\mathrm{Sa}[0.042]$ & -4.17 & 1.65 & -1.90 & 0.51552 & 0.63255 & 0.0075 & -0.21 & 0.65 \\
\hline $\mathrm{Sa}[0.044]$ & -4.07 & 1.65 & -1.92 & 0.51552 & 0.63255 & 0.0075 & -0.20 & 0.66 \\
\hline $\mathrm{Sa}[0.045]$ & -4.01 & 1.65 & -1.92 & 0.51552 & 0.63255 & 0.0075 & -0.20 & 0.66 \\
\hline $\mathrm{Sa}[0.046]$ & -3.96 & 1.65 & -1.93 & 0.51552 & 0.63255 & 0.0075 & -0.19 & 0.67 \\
\hline $\mathrm{Sa}[0.048]$ & -3.86 & 1.66 & -1.96 & 0.51552 & 0.63255 & 0.0075 & -0.19 & 0.67 \\
\hline $\mathrm{Sa}[0.050]$ & -3.78 & 1.66 & -1.98 & 0.51552 & 0.63255 & 0.0075 & -0.18 & 0.68 \\
\hline $\mathrm{Sa}[0.055]$ & -3.55 & 1.65 & -2.01 & 0.51552 & 0.63255 & 0.0075 & -0.18 & 0.69 \\
\hline $\mathrm{Sa}[0.060]$ & -3.33 & 1.65 & -2.05 & 0.51552 & 0.63255 & 0.0075 & -0.17 & 0.69 \\
\hline $\mathrm{Sa}[0.065]$ & -3.08 & 1.64 & -2.08 & 0.51552 & 0.63255 & 0.0075 & -0.16 & 0.69 \\
\hline $\mathrm{Sa}[0.067]$ & -2.99 & 1.64 & -2.09 & 0.51552 & 0.63255 & 0.0075 & -0.15 & 0.70 \\
\hline $\mathrm{Sa}[0.070]$ & -2.89 & 1.63 & -2.10 & 0.51552 & 0.63255 & 0.0075 & -0.14 & 0.70 \\
\hline $\mathrm{Sa}[0.075]$ & -2.73 & 1.61 & -2.09 & 0.51552 & 0.63255 & 0.0075 & -0.13 & 0.70 \\
\hline $\mathrm{Sa}[0.080]$ & -2.62 & 1.59 & -2.09 & 0.51552 & 0.63255 & 0.0075 & -0.13 & 0.70 \\
\hline $\mathrm{Sa}[0.085]$ & -2.55 & 1.56 & -2.07 & 0.51552 & 0.63255 & 0.0075 & -0.13 & 0.69 \\
\hline $\mathrm{Sa}[0.090]$ & -2.49 & 1.53 & -2.04 & 0.51552 & 0.63255 & 0.0075 & -0.14 & 0.68 \\
\hline $\mathrm{Sa}[0.095]$ & -2.43 & 1.51 & -2.02 & 0.51552 & 0.63255 & 0.0075 & -0.14 & 0.66 \\
\hline $\mathrm{Sa}[0.100]$ & -2.37 & 1.49 & -2.01 & 0.51552 & 0.63255 & 0.0075 & -0.15 & 0.66 \\
\hline $\mathrm{Sa}[0.110]$ & -2.32 & 1.47 & -1.98 & 0.51552 & 0.63255 & 0.0075 & -0.17 & 0.64 \\
\hline $\mathrm{Sa}[0.120]$ & -2.34 & 1.43 & -1.93 & 0.51552 & 0.63255 & 0.0075 & -0.19 & 0.64 \\
\hline $\mathrm{Sa}[0.130]$ & -2.38 & 1.38 & -1.87 & 0.51552 & 0.63255 & 0.0075 & -0.22 & 0.64 \\
\hline $\mathrm{Sa}[0.133]$ & -2.41 & 1.37 & -1.86 & 0.51552 & 0.63255 & 0.0075 & -0.23 & 0.64 \\
\hline $\mathrm{Sa}[0.140]$ & -2.52 & 1.35 & -1.81 & 0.51552 & 0.63255 & 0.0075 & -0.24 & 0.63 \\
\hline $\mathrm{Sa}[0.150]$ & -2.66 & 1.35 & -1.78 & 0.51552 & 0.63255 & 0.0075 & -0.25 & 0.64 \\
\hline $\mathrm{Sa}[0.160]$ & -2.78 & 1.37 & -1.76 & 0.51552 & 0.63255 & 0.0075 & -0.24 & 0.65 \\
\hline $\mathrm{Sa}[0.170]$ & -2.82 & 1.39 & -1.77 & 0.51552 & 0.63255 & 0.0075 & -0.26 & 0.65 \\
\hline $\mathrm{Sa}[0.180]$ & -2.95 & 1.41 & -1.77 & 0.51552 & 0.63255 & 0.0075 & -0.27 & 0.65 \\
\hline $\mathrm{Sa}[0.190]$ & -3.11 & 1.42 & -1.75 & 0.51552 & 0.63255 & 0.0075 & -0.29 & 0.65 \\
\hline $\mathrm{Sa}[0.200]$ & -3.29 & 1.42 & -1.72 & 0.51552 & 0.63255 & 0.0075 & -0.31 & 0.65 \\
\hline $\mathrm{Sa}[0.220]$ & -3.68 & 1.44 & -1.65 & 0.51552 & 0.63255 & 0.0075 & -0.32 & 0.66 \\
\hline $\mathrm{Sa}[0.240]$ & -4.11 & 1.49 & -1.62 & 0.51552 & 0.63255 & 0.0075 & -0.32 & 0.67 \\
\hline $\mathrm{Sa}[0.250]$ & -4.37 & 1.52 & -1.60 & 0.51552 & 0.63255 & 0.0075 & -0.33 & 0.68 \\
\hline $\mathrm{Sa}[0.260]$ & -4.62 & 1.55 & -1.58 & 0.51552 & 0.63255 & 0.0075 & -0.35 & 0.70 \\
\hline $\mathrm{Sa}[0.280]$ & -5.06 & 1.59 & -1.55 & 0.51552 & 0.63255 & 0.0075 & -0.39 & 0.71 \\
\hline $\mathrm{Sa}[0.290]$ & -5.21 & 1.61 & -1.54 & 0.51552 & 0.63255 & 0.0075 & -0.41 & 0.71 \\
\hline
\end{tabular}


Appendix Table A1. (Continued)

\begin{tabular}{|c|c|c|c|c|c|c|c|c|}
\hline Parameter & $\mathrm{C}_{1}$ & $\mathbf{C}_{2}$ & $\mathrm{C}_{3}$ & $\mathrm{C}_{4}$ & $\mathrm{C}_{5}$ & $\mathrm{C}_{6}$ & $\mathbf{C}_{7}$ & $\sigma$ \\
\hline $\mathrm{Sa}[0.300]$ & -5.40 & 1.64 & -1.54 & 0.51552 & 0.63255 & 0.0075 & -0.43 & 0.72 \\
\hline $\mathrm{Sa}[0.320]$ & -5.75 & 1.69 & -1.53 & 0.51552 & 0.63255 & 0.0075 & -0.45 & 0.74 \\
\hline $\mathrm{Sa}[0.340]$ & -6.17 & 1.73 & -1.50 & 0.51552 & 0.63255 & 0.0075 & -0.47 & 0.76 \\
\hline $\mathrm{Sa}[0.350]$ & -6.40 & 1.75 & -1.47 & 0.51552 & 0.63255 & 0.0075 & -0.48 & 0.76 \\
\hline $\mathrm{Sa}[0.360]$ & -6.63 & 1.76 & -1.44 & 0.51552 & 0.63255 & 0.0075 & -0.48 & 0.77 \\
\hline $\mathrm{Sa}[0.380]$ & -7.04 & 1.78 & -1.39 & 0.51552 & 0.63255 & 0.0075 & -0.48 & 0.79 \\
\hline $\mathrm{Sa}[0.400]$ & -7.39 & 1.81 & -1.35 & 0.51552 & 0.63255 & 0.0075 & -0.49 & 0.80 \\
\hline $\mathrm{Sa}[0.420]$ & -7.78 & 1.84 & -1.31 & 0.51552 & 0.63255 & 0.0075 & -0.49 & 0.82 \\
\hline $\mathrm{Sa}[0.440]$ & -8.13 & 1.86 & -1.27 & 0.51552 & 0.63255 & 0.0075 & -0.51 & 0.83 \\
\hline $\mathrm{Sa}[0.450]$ & -8.30 & 1.86 & -1.24 & 0.51552 & 0.63255 & 0.0075 & -0.52 & 0.83 \\
\hline $\mathrm{Sa}[0.460]$ & -8.47 & 1.87 & -1.21 & 0.51552 & 0.63255 & 0.0075 & -0.53 & 0.84 \\
\hline $\mathrm{Sa}[0.480]$ & -8.77 & 1.89 & -1.17 & 0.51552 & 0.63255 & 0.0075 & -0.54 & 0.85 \\
\hline $\mathrm{Sa}[0.500]$ & -9.02 & 1.89 & -1.13 & 0.51552 & 0.63255 & 0.0075 & -0.55 & 0.87 \\
\hline $\mathrm{Sa}[0.550]$ & -9.68 & 1.91 & -1.03 & 0.51552 & 0.63255 & 0.0075 & -0.58 & 0.91 \\
\hline $\mathrm{Sa}[0.600]$ & -10.21 & 1.97 & -1.01 & 0.51552 & 0.63255 & 0.0075 & -0.60 & 0.92 \\
\hline $\mathrm{Sa}[0.650]$ & -10.71 & 2.01 & -0.97 & 0.51552 & 0.63255 & 0.0075 & -0.64 & 0.95 \\
\hline $\mathrm{Sa}[0.667]$ & -10.88 & 2.02 & -0.95 & 0.51552 & 0.63255 & 0.0075 & -0.65 & 0.96 \\
\hline $\mathrm{Sa}[0.700]$ & -11.25 & 2.09 & -0.96 & 0.51552 & 0.63255 & 0.0075 & -0.67 & 0.98 \\
\hline $\mathrm{Sa}[0.750]$ & -11.77 & 2.21 & -1.01 & 0.51552 & 0.63255 & 0.0075 & -0.69 & 1.00 \\
\hline $\mathrm{Sa}[0.800]$ & -12.25 & 2.27 & -0.99 & 0.51552 & 0.63255 & 0.0075 & -0.72 & 1.01 \\
\hline $\mathrm{Sa}[0.850]$ & -12.66 & 2.32 & -0.98 & 0.51552 & 0.63255 & 0.0075 & -0.74 & 1.03 \\
\hline $\mathrm{Sa}[0.900]$ & -13.02 & 2.34 & -0.95 & 0.51552 & 0.63255 & 0.0075 & -0.76 & 1.06 \\
\hline $\mathrm{Sa}[0.950]$ & -13.37 & 2.40 & -0.97 & 0.51552 & 0.63255 & 0.0075 & -0.79 & 1.08 \\
\hline $\mathrm{Sa}[1.000]$ & -13.73 & 2.48 & -1.00 & 0.51552 & 0.63255 & 0.0075 & -0.82 & 1.09 \\
\hline $\mathrm{Sa}[1.100]$ & -14.33 & 2.60 & -1.06 & 0.51552 & 0.63255 & 0.0075 & -0.86 & 1.10 \\
\hline $\mathrm{Sa}[1.200]$ & -14.70 & 2.68 & -1.10 & 0.51552 & 0.63255 & 0.0075 & -0.86 & 1.11 \\
\hline $\mathrm{Sa}[1.300]$ & -15.04 & 2.77 & -1.16 & 0.51552 & 0.63255 & 0.0075 & -0.88 & 1.12 \\
\hline $\mathrm{Sa}[1.400]$ & -15.59 & 2.84 & -1.17 & 0.51552 & 0.63255 & 0.0075 & -0.94 & 1.08 \\
\hline $\mathrm{Sa}[1.500]$ & -15.86 & 2.87 & -1.18 & 0.51552 & 0.63255 & 0.0075 & -0.95 & 1.08 \\
\hline $\mathrm{Sa}[1.600]$ & -16.07 & 2.86 & -1.15 & 0.51552 & 0.63255 & 0.0075 & -0.97 & 1.06 \\
\hline $\mathrm{Sa}[1.700]$ & -16.15 & 2.87 & -1.18 & 0.51552 & 0.63255 & 0.0075 & -0.98 & 1.06 \\
\hline $\mathrm{Sa}[1.800]$ & -16.25 & 2.87 & -1.19 & 0.51552 & 0.63255 & 0.0075 & -0.98 & 1.06 \\
\hline $\mathrm{Sa}[1.900]$ & -16.39 & 2.88 & -1.20 & 0.51552 & 0.63255 & 0.0075 & -0.99 & 1.06 \\
\hline $\mathrm{Sa}[2.000]$ & -16.45 & 2.83 & -1.15 & 0.51552 & 0.63255 & 0.0075 & -0.99 & 1.04 \\
\hline $\mathrm{Sa}[2.200]$ & -16.54 & 2.81 & -1.15 & 0.51552 & 0.63255 & 0.0075 & -0.97 & 1.02 \\
\hline $\mathrm{Sa}[2.400]$ & -16.58 & 2.80 & -1.18 & 0.51552 & 0.63255 & 0.0075 & -0.96 & 1.01 \\
\hline $\mathrm{Sa}[2.500]$ & -16.59 & 2.79 & -1.19 & 0.51552 & 0.63255 & 0.0075 & -0.96 & 1.01 \\
\hline $\mathrm{Sa}[2.600]$ & -16.61 & 2.78 & -1.20 & 0.51552 & 0.63255 & 0.0075 & -0.96 & 1.00 \\
\hline $\mathrm{Sa}[2.800]$ & -16.65 & 2.78 & -1.23 & 0.51552 & 0.63255 & 0.0075 & -0.95 & 0.99 \\
\hline $\mathrm{Sa}[3.000]$ & -16.75 & 2.77 & -1.24 & 0.51552 & 0.63255 & 0.0075 & -0.95 & 0.98 \\
\hline $\mathrm{Sa}[3.200]$ & -16.79 & 2.77 & -1.26 & 0.51552 & 0.63255 & 0.0075 & -0.94 & 0.97 \\
\hline $\mathrm{Sa}[3.400]$ & -16.79 & 2.75 & -1.27 & 0.51552 & 0.63255 & 0.0075 & -0.93 & 0.94 \\
\hline $\mathrm{Sa}[3.500]$ & -16.77 & 2.74 & -1.27 & 0.51552 & 0.63255 & 0.0075 & -0.91 & 0.94 \\
\hline $\mathrm{Sa}[3.600]$ & -16.77 & 2.74 & -1.29 & 0.51552 & 0.63255 & 0.0075 & -0.90 & 0.93 \\
\hline $\mathrm{Sa}[3.800]$ & -16.84 & 2.72 & -1.28 & 0.51552 & 0.63255 & 0.0075 & -0.88 & 0.92 \\
\hline
\end{tabular}


Appendix Table A1. (Continued)

\begin{tabular}{|c|c|c|c|c|c|c|c|c|}
\hline Parameter & $\mathrm{C}_{1}$ & $\mathrm{C}_{2}$ & $\mathrm{C}_{3}$ & $\mathrm{C}_{4}$ & $\mathrm{C}_{5}$ & $\mathrm{C}_{6}$ & $\mathbf{C}_{7}$ & $\sigma$ \\
\hline $\mathrm{Sa}[4.000]$ & -16.87 & 2.71 & -1.28 & 0.51552 & 0.63255 & 0.0075 & -0.87 & 0.91 \\
\hline $\mathrm{Sa}[4.200]$ & -16.91 & 2.71 & -1.30 & 0.51552 & 0.63255 & 0.0075 & -0.86 & 0.91 \\
\hline $\mathrm{Sa}[4.400]$ & -17.08 & 2.73 & -1.31 & 0.51552 & 0.63255 & 0.0075 & -0.85 & 0.89 \\
\hline $\mathrm{Sa}[4.600]$ & -17.11 & 2.71 & -1.30 & 0.51552 & 0.63255 & 0.0075 & -0.83 & 0.88 \\
\hline $\mathrm{Sa}[4.800]$ & -17.18 & 2.71 & -1.30 & 0.51552 & 0.63255 & 0.0075 & -0.83 & 0.87 \\
\hline $\mathrm{Sa}[5.000]$ & -17.22 & 2.69 & -1.29 & 0.51552 & 0.63255 & 0.0075 & -0.83 & 0.87 \\
\hline $\mathrm{Sa}[5.500]$ & -17.35 & 2.67 & -1.29 & 0.51552 & 0.63255 & 0.0075 & -0.82 & 0.87 \\
\hline $\mathrm{Sa}[6.000]$ & -17.45 & 2.61 & -1.24 & 0.51552 & 0.63255 & 0.0075 & -0.81 & 0.86 \\
\hline $\mathrm{Sa}[6.500]$ & -17.55 & 2.57 & -1.20 & 0.51552 & 0.63255 & 0.0075 & -0.79 & 0.85 \\
\hline $\mathrm{Sa}[7.000]$ & -17.61 & 2.53 & -1.18 & 0.51552 & 0.63255 & 0.0075 & -0.77 & 0.82 \\
\hline $\mathrm{Sa}[7.500]$ & -17.73 & 2.45 & -1.09 & 0.51552 & 0.63255 & 0.0075 & -0.73 & 0.82 \\
\hline $\mathrm{Sa}[8.000]$ & -17.83 & 2.43 & -1.07 & 0.51552 & 0.63255 & 0.0075 & -0.72 & 0.81 \\
\hline $\mathrm{Sa}[8.500]$ & -17.92 & 2.42 & -1.06 & 0.51552 & 0.63255 & 0.0075 & -0.73 & 0.80 \\
\hline $\mathrm{Sa}[9.000]$ & -17.96 & 2.40 & -1.05 & 0.51552 & 0.63255 & 0.0075 & -0.71 & 0.79 \\
\hline $\mathrm{Sa}[9.500]$ & -17.97 & 2.31 & -0.97 & 0.51552 & 0.63255 & 0.0075 & -0.68 & 0.78 \\
\hline $\mathrm{Sa}[10.000]$ & -17.98 & 2.29 & -0.96 & 0.51552 & 0.63255 & 0.0075 & -0.68 & 0.78 \\
\hline
\end{tabular}

